\title{
Continuous cardiac output measurements do not agree with conventional bolus thermodilution car- diac output determination
}

\author{
[Les mesures continues du débit cardiaque ne concordent pas avec la détermina- \\ tion traditionnelle du débit cardiaque utilisant un bolus et la thermodilution]
}

Christian Zöllner MD, * Alwin E. Goetz MD, * Marion Weis MD, * Karl Mörstedt MD, ${ }^{*}$ Bodo Pichler MD, *

Peter Lamm MD, $\dagger$ Erich Kilger MD, ${ }^{*}$ Mathias Haller $\mathrm{MD}^{*}$

Purpose: To evaluate the performance of two different continuous cardiac output monitoring systems based on the thermodilution principle in critically ill patients.

Methods: Nineteen cardiac surgical patients were randomly assigned to continuous cardiac output monitoring using one of the two systems under study (group I, IntelliCath ${ }^{\text {TM }}$ catheter, $n=9$; group II, Opti-Q ${ }^{\text {TM }}$ catheter, $n=10$ ). Each patient was studied over a period of three hours. Conventional bolus thermodilution cardiac output measurements were carried out every 15 min leading to 13 measurements in each patient. The continuous cardiac output values were compared with the bolus thermodilution measurements. Bias (mean difference between continuous and bolus thermodilu tion) and precision (SD of differences) were calculated as a measure of agreement between the respective continuous method and conventional bolus thermodilution.

Results: The range of measured cardiac outputs was 3.8-15.4 $\mathrm{L} \cdot \mathrm{min}^{-1}\left(\right.$ IntelliCath $\left.{ }^{\mathrm{TM}}\right)$ and 3.5-8.3 L. $\mathrm{min}^{-1}\left(\mathrm{OptiQ}^{\mathrm{TM}}\right)$. Bias and precision was $0.06 \pm 0.76 \mathrm{~L} \cdot \mathrm{min}^{-1}$ (IntelliCath $^{\text {TM }}$ ) and $-0.04 \pm 0.74$ $L \cdot \mathrm{min}^{-1}\left(\mathrm{OptiQ}^{\mathrm{TM}}\right)$, respectively. There was no difference in bias between the two systems $(P=0.38)$. \pm 2 SD of the differences (i.e., $95 \%$ of the differences) did not fall within the predetermined limits of agreement of $\pm 0.5 \mathrm{~L} \cdot \mathrm{min}^{-1}$.

Conclusions: There was no difference between the two systems regarding the agreement with conventional bolus thermodilution as the standard. A discrepancy between bolus and continuous thermodilution cardiac output measurement techniques above the clinically acceptable limits suggest that they are not interchangeable.

Objectif : Évaluer, chez des patients gravement malades, la performance de deux systèmes de monitorage continu du débit cardiaque fondés sur le principe de la thermodilution.
Méthode : Dix-neuf patients de cardiochirurgie ont été répartis de façon aléatoire en deux groupes de monitorage continu du débit cardiaque : le groupe I, avec une sonde IntelliCath ${ }^{\mathrm{TM}}, n=9$; le groupe II, avec une sonde Opti- $\left.Q^{\mathrm{TM}}, n=10\right)$. Chaque patient a été observé pendant trois heures. Les mesures traditionnelles du débit cardiaque par thermodilution d'un bolus ont été faites toutes les 15 min, pour un total de 13 mesures par patient. Les valeurs continues du débit cardiaque ont été comparées aux mesures par thermodilution d'un bolus. Le biais (différence moyenne entre la thermodilution continue et celle d'un bolus) et la précision (écart type des différences) ont été calculés comme mesure de concordance entre la méthode continue et la thermodilution traditionnelle d'un bolus.

Résultats : Les limites des débits cardiaques mesurés ont été de 3,8

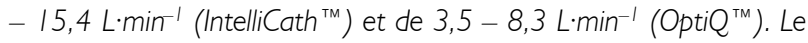
biais et la précision ont été de 0,06 $\pm 0,76 \mathrm{~L} \cdot \mathrm{min}^{-1}$ (IntelliCath ${ }^{\mathrm{TM}}$ ) et de $-0,04 \pm 0,74 \mathrm{~L} \cdot \mathrm{min}^{-1}\left(\mathrm{Opti} \mathrm{Q}^{\mathrm{TM}}\right)$, respectivement. Le biais a été comparable entre les deux sondes $(P=0,38)$; et \pm 2 écarts types des différences (95\% des différences) n'étaient pas compris dans les limites de concordance prédéterminées de $\pm 0,5 \mathrm{~L} \cdot \mathrm{min}^{-1}$.

Conclusion : Les deux systèmes n'ont pas présenté de différence entre eux quant à la concordance avec la norme traditionnelle de la thermodilution d'un bolus. Une divergence entre les mesures du débit cardiaque par themodilution d'un bolus et thermodilution continue au delà des limites acceptables en pratique permet d'affirmer que ces deux techniques ne sont pas interchangeables.

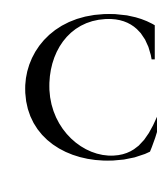

ONTINUOUS monitoring of vital parameters such as oxygenation, blood pressure, and heart rate is available and now standard practice in critical care medicine. Cardiac output is one of the major determinants of

From the Departments of Anesthesiology, ${ }^{*}$ and Cardiac Surgery, $\nmid$ Ludwig-Maximilians University of Munich, Munich, Germany. Address correspondence to: Dr. Mathias Haller, Institut für Anaesthesiologie, Klinikum Grosshadern, Marchioninistrasse 15, 81377

München, Germany. Phone: +49-89-7095-2923; Fax: +49-89-7095-2822; E-mail: Mathias.Haller@bigfoot.de Accepted for publication April 2, 2001.

$2^{\text {nd }}$ revision accepted August 2, 2001. 
TABLE Bias (mean difference) and precision (SD of differences) for all cardiac output values and for cardiac output values $<10$ $\mathrm{L} \cdot \mathrm{min}^{-1}$ in the IntelliCath ${ }^{\mathrm{TM}}$ group

\begin{tabular}{lll}
\hline & Bias $\left(\right.$ L.min $\left.^{-1}\right)$ & Precision $\left(L \cdot\right.$ min $\left.^{-1}\right)$ \\
\hline IntelliCath $^{\mathrm{TM}}$ (CCO - TD) & -0.09 & 1.04 \\
OptiQ $^{\mathrm{TM}} \quad(\mathrm{CCO}-\mathrm{TD})$ & -0.04 & 0.74 \\
Cardiac output $<$ 10 L.min $^{-1}$ & & \\
IntelliCath $^{\mathrm{TM}}$ (CCO - TD) & +0.06 & 0.76 \\
\hline
\end{tabular}

$\mathrm{TD}=$ conventional bolus thermodilution results; $\mathrm{CCO}=$ continuous cardiac output results.

organ perfusion. Since the early 1970s an intermittent method of measuring cardiac output using the thermodilution principle has been clinically available. ${ }^{1,2}$ Since then, there have been many efforts to measure cardiac ouput continuously. In 1992 Yelderman $e t a l^{3}$ introduced a new continuous cardiac output monitoring system into clinical practice (IntelliCath ${ }^{\mathrm{TM}}$ and Vigilance Monitor ${ }^{\mathrm{TM}}$, Baxter Edwards Critical-Care, Irvine, CA, USA) using heat as the indicator. The performance of another continuous cardiac output monitoring system (Opti- $^{\mathrm{TM}}$, Abbott Laboratories, Chicago, IL, USA) using the same basic continuous thermodilution principle but different signal generation and signal processing technologies has recently been evaluated. ${ }^{4-6}$

We investigated the performance of both systems (IntelliCath ${ }^{\mathrm{TM}}$ and Opti- $\mathrm{Q}^{\mathrm{TM}}$ ) which are available for about the same price in a randomized study and compared the continuous cardiac output values delivered by either system with conventional bolus thermodilution cardiac output measurements.

Methods

The study was approved by the Ethics Committee of the Faculty of Medicine of the Ludwig-MaximiliansUniversity in Munich. All patients gave their written informed consent to participate in the study. Nineteen patients ( 16 male, three female) with a median age of $63 \mathrm{yr}$ (range 34-76) were included. All patients were studied after cardiac surgery during periods of hemodynamic stability.

The indications for cardiac surgery were aortic/mitral valve replacement and/or coronary artery revascularization. The decision to insert pulmonary artery catheters was made by the attending physician. The pulmonary artery catheters were inserted before the start of the operation via the internal jugular vein through a 8.5-French introducer. The position of the catheter was confirmed using pressure control from the proximal and distal port of the catheter and chest $x$-ray.

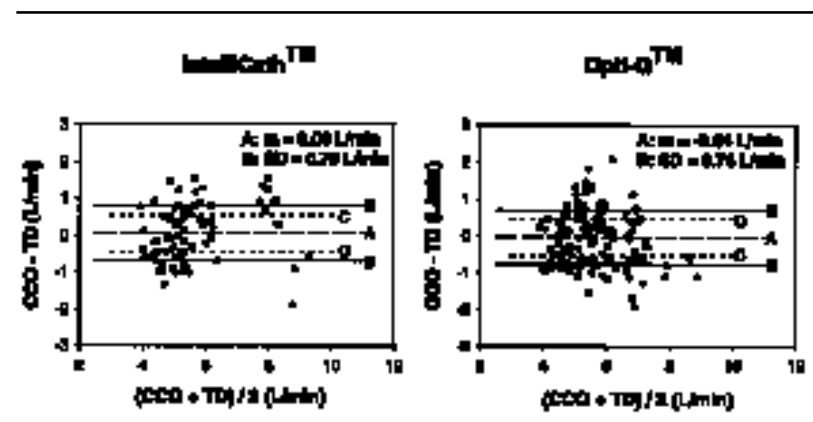

FIGURE Differences between the results of continuous (CCO) and bolus (TD) thermodilution measurements plotted over the average of each pair of values for cardiac output values $<10$ $\mathrm{L} \cdot \mathrm{min}^{-1}$. Line $\mathrm{A}=$ mean differences; Line $\mathrm{B}= \pm \mathrm{SD}$ of the differences; Line $\mathrm{C}=$ differences chosen to be acceptable $\left( \pm 0.5 \mathrm{~L} \cdot \mathrm{min}^{-1}\right)$.

All patients had arterial catheters in place for continuous monitoring of arterial pressure perioperatively.

Conventional pulmonary bolus thermodilution cardiac output was measured with the same pulmonary artery catheter which was used for the continuous measurements. Ten mililiters of isotonic saline at 7 to $9^{\circ} \mathrm{C}$ were injected through the injectate port of the pulmonary artery catheter using a closed injectate system (CO-Set plus, Baxter Edwards Critical-Care, Irvine, CA, USA). Measurements were carried out in triplicate at random points of the respiratory cycle. A variation of $\pm 15 \%$ within the triplicate measurements was defined to be acceptable. Values derived from measurements with unacceptable thermodilution curves were discarded. All thermodilution measurements were carried out by the same investigator to avoid interobserver variations.

Patients were randomized prospectively to receive either an IntelliCath ${ }^{\mathrm{TM}}$ or an OptiQ ${ }^{\mathrm{TM}}$ catheter. The study was planned to be terminated when one of the two groups reached the intended number of included patients per group $(n=10)$. The measurements were carried out over a period of three hours. Planned bolus cardiac output determinations were done every $15 \mathrm{~min}$ leading to a total of 13 measurements per patient. Due to the measuring technique, continuous measurement of cardiac output has to be interrupted during bolus thermodilution measurements. Therefore, at each measuring point continuous cardiac output was recorded before and after the bolus thermodilution measurements.

The average of the results read from the continuous cardiac output monitor immediately before as well as after the bolus determinations was compared with the 
mean of the triplicate bolus thermodilution values. To compare the results we used the method described by Bland and Altman, ${ }^{7}$ calculating the mean (bias) $\pm \mathrm{SD}$ (as a measure of precision) of the differences between the values obtained. The differences between each pair of values were plotted over the average of each pair. We determined the limits within which the two methods will be judged to be interchangeable to $\pm 0.5 \mathrm{~L} \cdot \mathrm{min}^{-1} .7,8$ To test the data for normality we used the KolmogorovSmirnov test (SigmaStat $\AA$ ). Differences within one group of patients were tested for statistical significance using the student's $t$ tests (if data were normally distributed) or Wilcoxon rank sum tests (not normally distributed data). Student's $t$ tests for unpaired data were used to test for differences between groups. A $P$-value of 0.05 or less was considered significant.

Results

The range of continuously measured cardiac outputs was 3.8-15.4 L. $\mathrm{min}^{-1}$ (mean: $7.44 \mathrm{~L} \cdot \mathrm{min}^{-1}$, IntelliCath $^{\mathrm{TM}}$ ) and $3.5-8.3 \mathrm{~L} \cdot \mathrm{min}^{-1}$ (mean: $5.6 \mathrm{~L} \cdot \mathrm{min}^{-1}$, OptiQ $\left.{ }^{\mathrm{TM}}\right)$, respectively. A total of 117 measurements was carried out in the nine patients randomized to the IntelliCath $^{\mathrm{TM}}$ group and 130 measurements in ten patients randomized to the $\mathrm{OptiQ}^{\mathrm{TM}}$ group. Three patients randomized to the Intellicath ${ }^{\mathrm{TM}}$ group had cardiac output values $>10 \mathrm{~L} \cdot \mathrm{min}^{-1}$ compared with none in the OptiQ ${ }^{\mathrm{TM}}$ group. Bias (mean difference between continuous and bolus thermodilution values) and precision (SD of differences) of all patients are presented in the Table. The results of patients of the Intellicath ${ }^{\mathrm{TM}}$ group with cardiac outputs $<10 \mathrm{~L} \cdot \mathrm{min}^{-1}$ are given separately (Table). There was no difference between the two groups with respect to the agreement of continuous and bolus thermodilution values ("bias", $P=0.38$ ). $49 \%$ (64) of all data points in the OptiQ ${ }^{\mathrm{TM}}$ group and $46 \%$ (36) in the Intellicath ${ }^{\mathrm{TM}}$ group are within the chosen acceptable difference of $\pm 0.5 \mathrm{~L} \cdot \mathrm{min}^{-1}$.

Using either the continuous values obtained before or after the bolus determinations does not change the results compared with using the average of both values. No malfunctions of the continuous cardiac output computer systems occurred during the study period.

\section{Discussion}

The established method to measure cardiac output in the clinical setting is the bolus thermodilution method. However, because hemodynamic conditions may change rapidly many efforts have been made to develop a method which measures cardiac output continuously. Cardiac output determinations using Doppler technology yielded controversial results ${ }^{9}$ and the transthoracic electrical bioimpedance method reveals clinically significant errors compared with conventional bolus thermodilution. ${ }^{10,11}$

Initial efforts to develop clinically applicable continuous cardiac output monitors based on thermodilution failed because of the unfavourable ratio of the heat signal to the background thermal noise in the pulmonary artery. ${ }^{12,13}$ With the introduction of a new technology of signal processing Yelderman. ${ }^{14}$ reported in 1990 on a monitoring system using the thermodilution principle and heat as an indicator to measure cardiac output. The pseudo random input (heating signal power) and output (change of the blood temperature) sequence analyses allow the subtraction of thermal noise (respiration effects, drug infusions, slower long term temperature changes) from the desired temperature signal.

Since 1992 several groups have investigated this technology using the IntelliCath ${ }^{\mathrm{TM}}$ catheter with different reference techniques in various clinical situations $^{15-21}$ and found similar results. This technique seems to be reasonably accurate, reliable, applicable and safe in routine clinical practice. However, the response time was rather slow for the immediate detection of acute changes in cardiac output. The in vitro response time of a change in cardiac output of the IntelliCath ${ }^{\mathrm{TM}}$ and the Opti- $\mathrm{Q}^{\mathrm{TM}}$ catheter was between five to $15 \mathrm{~min}^{22}$ Some clinical conditions such as the rapid infusion of cold fluids may interfere with the continuous cardiac output measurements. ${ }^{21}$

Burchell et al. ${ }^{4}$ recently reported on the performance of another continuous cardiac output monitoring system (Opti- $\left.\mathrm{Q}^{\mathrm{TM}}\right)$ using basically the same heating technology but different signal generation and signal processing algorithms. In contrast to the IntelliCath $^{\mathrm{TM}}$ algorithm the OptiQ ${ }^{\mathrm{TM}}$ system uses different frequencies with an input square wave heating signal. The multiple frequencies are used to maximize the signal to noise ratio, however, one fundamental frequency of $20 \mathrm{sec}$ of a 40 -sec repetitive on-off cycle is normally used. ${ }^{5,22}$ After each 20 -sec signal thermodilution washout curves are analyzed separately.

The IntelliCath ${ }^{\mathrm{TM}}$ continuous cardiac output computer measures cardiac output with a stochastic system identification technique. A random generator activates the heating filament for $1-4 \mathrm{sec}$ periods. A fastresponse thermistor measures the changes in the pulmonary blood temperature and after an observation interval of ten heating runs, the cross-correlator constructs one classical indicator washout curve to calculate cardiac output. ${ }^{14}$ In spite of the similarity of the basic principle (thermodilution using heat as the indicator) the two systems use different procedures and calculations to obtain continuous cardiac output val- 
ues. These differences could lead to differences in performance and reliability between the two systems. We therefore evaluated the performance of these two different continuous cardiac output monitoring systems in the clinical setting.

One limitation of the study is that there is no "golden standard" with which the continuous cardiac output values may be compared. Bolus thermodilution cardiac output was the criterion standard in the present study. Errors in bolus cardiac output measurements may be caused by random or systematic effects. Random errors are quantified by the coefficient of variation of the thermodilution measurements, which was found to be equal in both groups $(5.6 \%)$. Both catheter systems use the same algorithm to calculate the conventional bolus thermodilution cardiac output.

For obvious reasons the two systems could not be applied to the same patients to rule out interindividual patient differences. As a consequence, the range of measured cardiac outputs was different in both groups with values $>10 \mathrm{~L} \cdot \mathrm{min}^{-1}$ occurring only in the IntelliCath ${ }^{\mathrm{TM}}$ group. This unequal patient distribution was attributed to the randomization process. We found similar results in bias and precision for both systems excluding the three patients with cardiac output values $>10 \mathrm{~L} \cdot \mathrm{min}^{-1}$. The increasing standard deviation of the differences $\left(1.04 \mathrm{~L} \cdot \mathrm{min}^{-1}\right)$ in the IntelliCath ${ }^{\mathrm{TM}}$ group including cardiac output values $>10 \mathrm{~L} \cdot \mathrm{min}^{-1}$ may be the result of a higher variability of both the thermodilution and the continuous cardiac output methods due to a lower signal to noise ratio as a consequence of high blood flows.

In summary, this study demonstrates that both systems to measure cardiac output continuously performed equally. However, with respect to conventional bolus thermodilution cardiac output measurement the results of continuous cardiac output methods should be regarded with caution. A discrepancy between both measurement techniques above the clinically acceptable limits suggest that they are not interchangeable.

\section{References}

1 Ganz W, Donoso R, Marcus HS, Forrester JS, Swan $H J C$ A new technique for measurement of cardiac output by thermodilution in man. Am J Cardiol 1971; 27: 392-6.

2 Forrester JS, Ganz W, Diamond G, McHugh T, Chonette $D W$, Swan HJC Thermodilution cardiac output determination with a single flow-directed catheter. Am Heart J 1972; 83: 306-11.

3 Yelderman ML, Ramsay MA, Quinn MD, Paulsen $A W$, McKown RC, Gillmann HP. Continuous thermodilution cardiac output measurement in intensive care unit patients. J Cardiothorac Vasc Anesth 1992; 6: 270-4.
4 Burchell SA, $\Upsilon$ u M, Takiguchi SA, Obta RM, Myers SA. Evaluation of a continuous cardiac output and mixed venous oxygen saturation catheter in critically ill surgical patients. Crit Care Med 1997; 25: 388-91.

5 Mibm FG, Gettinger A, Hanson W, et al. A multicenter evaluation of a new continuous cardiac output pulmonary artery catheter system. Crit Care Med 1998; 26: $1346-50$.

6 Zöllner C, Polasek J, Kilger E, et al. Evaluation of a new continuous thermodilution cardiac output monitor in cardiac surgical patients: a prospective criterion standard study. Crit Care Med 1999; 27: 293-8.

7 Bland JM, Altman DG. Statistical methods for assessing agreement between two methods of clinical measurement. Lancet 1986; 8: 307-10.

8 Hardy J-F, Bélisle S, Gravel N. Incorrect analysis of data leads to incorrect conclusions. Can J Anaesth 1997; 44: 786-7.

9 Schmid ER, Spabn DR, Tornic M. Reliability of a new generation transesophageal doppler device for cardiac output monitoring. Anesth Analg 1993; 77: 971-9.

10 Sageman WS, Amundson DE. Thoracic electrical bioimpedance measurement of cardiac output in postaortocoronary bypass patients. Crit Care Med 1993; 21 : 1139-42.

11 Perrino AC, Lippman A, Ariyan C, O`Conner TZ, Luther $M$. Intraoperative cardiac output monitoring: Comparison of impedance cardiography and thermodilution. J Cardiothorac Vasc Anesth 1994; 8: 24-9.

12 Philip JH, Long MC, Quinn MD, Newbower RS. Continuous thermal measurement of cardiac output. IEEE Trans Biomed Eng 1984; 5: 393-400.

13 Normann RA, Johnson RW, Messinger JE, Sohrab B. A continuous cardiac output computer based on thermodilution principles. Ann Biomed Eng 1989; 17: 61-73.

14 Yelderman M. Continuous measurement of cardiac output with the use of stochastic system identification techniques. J Clin Monit 1990; 6: 322-32.

15 Hogue CW, Rosenbloom M, McCawley C, Lappas DG. Comparison of cardiac output measurement by continuous thermodilution with electromagnetometry in adult cardiac surgical patients. J Cardiothorac Vasc Anesth 1994; 8: 631-5.

16 Lichtenthal PR, Wade LD. Continuous cardiac output measurements. J Cardiothorac Vasc Anesth 1994; 8: $668-70$.

17 Jakobsen C-J, Melsen NC, Andresen EB. Continuous cardiac output measurements based on thermodilution technique in the perioperative period. J Cardiothorac Vasc Anesth 1994; 8 Suppl 3: 47.

18 Böttiger BW, Soder M, Rauch H, et al. Semi-continuous versus injectate cardiac output measurement in inten- 
sive care patients after cardiac surgery. Intensive Care

Med 1996; 22: 312-8.

19 Jacquet L, Hanique G, Glorieux D, Matte P, Goenen M. Analysis of the accuracy of continuous thermodilution cardiac output measurement. Intensive Care Med 1996; 22: 1125-9.

20 Boldt J, Menges T, Wollbrü̈k M, Hammermann H, Hempelmann $G$ Is continuous cardiac output measurement using thermodilution reliable in the critically ill patient? Crit Care Med 1994; 22: 1913-8.

21 Haller M, Zöllner C, Briegel J, Forst $H$. Evaluation of a new continuous thermodilution cardiac output monitor in critically ill patients: A prospective criterion standard study. Crit Care Med 1995; 23: 860-6.

22 Aranda M, Mibm FG, Garrett S, Mibm MN, Pearl RG. Continuous cardiac output catheters. Delay in in vitro response time after controlled flow changes.

Anesthesiology 1998; 89: 1592-5.

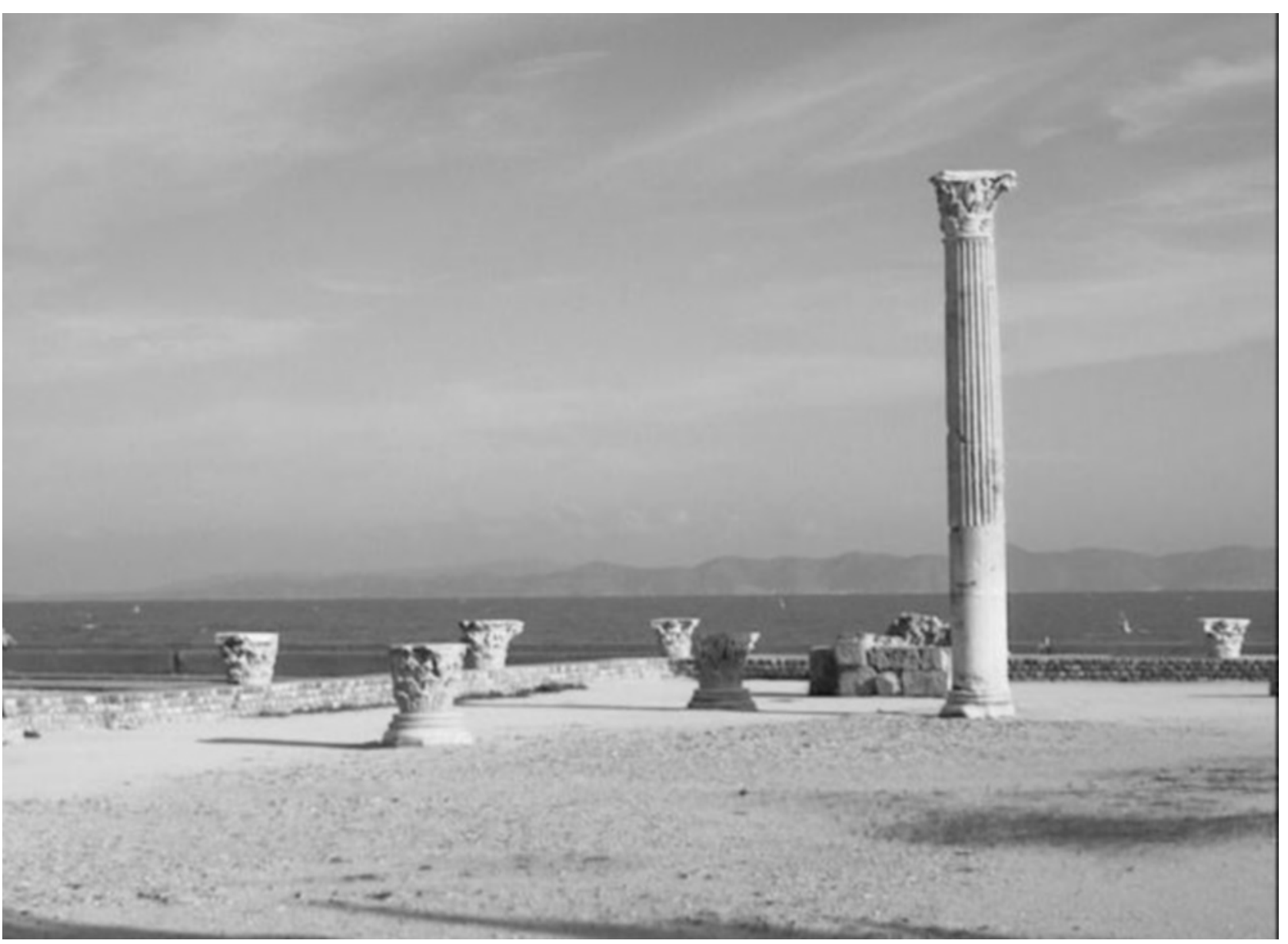

Antonin Baths, Carthage - Tunisia 